DOI 10.37882/2223-2982.2021.01.15

\title{
ПРОБЛЕМА ДЕЛИМИТАЦИИ И ДЕМАРКАЦИИ В КОНТЕКСТЕ КОНВЕНЦИИ О ПРАВОВОМ СТАТУСЕ КАСПИЙСКОГО МОРЯ
}

\section{THE PROBLEM OF DELIMITATION AND DEMARCATION IN THE CONTEXT OF THE CONVENTION ON THE LEGAL STATUS OF THE CASPIAN SEA}

\section{Kopylova}

Summary: The purpose of the study is to consider the problem of understanding the concepts of definition and delimitation in the context of legal status in the conditions of determinism of the phenomenon of differentiation and delimitation in which national zones, northern and southern spheres of demarcation, direct baselines and covering waters, national competencies and national sovereignty are expressed. the harmonious combination of this complex of concepts forms a mobile and effective system of interstate relations to resolve the caspian issue. The article deals with the practical application of the agreements reached by the Caspian states when signing the Convention on the Legal Status of the Caspian Sea. The definition of legal status is understood as the establishment and consolidation of rights and rules of conduct in order to streamline interstate relations and relations between the contracting Parties.

The scientific novelty of the study is to identify the problem, the essence of which is to search for and determine the historical and legal fate of the Caspian Sea, which is implemented through practical actions in the context of interstate agreements. Here, the term "feedback" refers to the processes of ratification of the Convention on the legal status of the Caspian Sea and subsequent demarcation within the framework of a set of agreements. As a result, the problem of delimitation and demarcation of the Caspian reservoir is revealed to be incomplete, where a key decision has been made, but at the moment it has not been fully implemented by the participants, which is related to the internal political issues of individual States in the region, as well as the global challenges of the present.

Keywords: legal status of the Caspian Sea; delineation; delimitation; covering waters; national zones; ratification; demarcation.
A ктуальность темы исследования обусловлена специфичностью условий и понятий, закрепленных в Конвенции о правовом статусе Каспийского моря, где возникают альтернативы в понимании теоретического и практического применения положений документа; вопрос о возможной тождественности или синхронизации понятий и их применения имеет место в процессе выполнения постулатов Конвенции и стимулирования ее практического осуществления.
Копылова Ирина Александровна

Аспирант, Кубанский государственный университет, irochkakostenko@gmail.com

Аннотация: Цель исследования - рассмотреть проблему понимания понятий определение и разграничение в контексте правового статуса в условиях детерминизма явления разграничения и делимитации в которых находят выражение национальные зоны, северная и южная сферы разграничения, прямые исходные линии и покрывающие воды, национальные компетенции и национальный суверенитет. Гармоничное сочетание данного комплекса понятий формирует подвижную и действенную систему межгосударственных отношений по решению Каспийского вопроса. В статье рассматривается практическое применение договоренностей, достигнутых прикаспийскими государствами при подписании Конвенции о правовом статусе Каспийского моря. Определение правового статуса понимается как установление и закрепление прав и правил поведения с целью упорядочения межгосударственных отношений и связей между договаривающимися сторонами.

Научная новизна исследования заключается в выявлении проблемы, суть которой в поиске и определении историко-правовой судьбы Каспийского моря, которая реализуется посредством практических действий в контексте межгосударственных договоренностей. Здесь под выражением «обратной связи» понимаем процессы ратификации Конвенции о правовом статусе Каспийского моря и последующей демаркации в рамках комплекса соглашений. В результате обнаруживается незавершенный характер проблемы делимитации и демаркации Каспийского водоема, где ключевое решение принято, но на данный момент полностью не реализовано участниками, что связано с внутриполитическими вопросами отдельных государств региона, а также общемировыми вызовами настоящего.

Ключевые слова: правовой статус Каспийского моря; разграничение; делимитация; покрывающие воды; национальные зоны; ратификация; демаркация.

Для достижения указанной цели по рассмотрению проблемы понимания понятий определение и разграничение в контексте правового статуса в условиях детерминизма явления разграничения и делимитации необходимо решить несколько задач: во-первых, рассмотреть понятие определение правового статуса Каспия, которое получило оригинальную историко-юридическую характеристику «моря-озера» в соответствии с принципами, закрепленными в Конвенции 2018 г.; во-вторых, выявить суть понятий делимитация и демар- 
кация, их отличительные черты в условиях реализации положений Конвенции о правовом статусе Каспийского моря; в-третьих, определить и проанализировать характер достигнутых пятисторонних договоренностей и значение сформировавшейся системы межгосударственных соглашений по каспийскому вопросу.

С целью выявления сути понятий делимитация и демаркация и их применения в контексте Конвенции о правовом статусе Каспийского моря в статье используются следующие методы исследования: историкосравнительный, метод анализа. Системно-структурный метод применим для комплексного рассмотрения как схожих, так и различительных характеристик понятий делимитация и демаркация в определении правового статуса Каспия, где образуется система критериев, необходимых для практического применения положений Конвенции в условиях их актуального понимания.

Теоретической базой исследования являются международно-правовые документы по Каспию, составители С.С. Жильцов, И.С. Зонн [3], аналитический сборник ОБСЕ за 2017 г. по вопросам делимитации и демаркации государственных границ в различных историко-политических условиях [2], работа профессора Э.Г Вартаньян [1] «Каспийский регион: проблемы и решения», в которых рассматривается проблема определения правого статуса Каспия, исторические условия ее возникновения и варианты ее разрешения. К настоящему моменту по данному вопросу сформирована эволюционная система взаимодействия государств Каспийского региона, отражающая динамизм и перспективы решения проблемы.

Практическая значимость исследования заключается в том, что выявляются и характеризуются понятия делимитации и демаркации государственных границ в контексте положений, закрепленных в Конвенции о правовом статусе Каспийского моря. Сопоставление указанных понятий выражает критерии их схожести и различий, а также в понимании практической значимости понятий, их реализации в целях развития как пятисторонних, так и двусторонних межгосударственных контактов.

Каспийский водоем не имеет выхода в воды мирового океана, что, с одной стороны, закрепляет за ним статус «озера». В то же время Каспий, в зависимости от своего размера, значения, ресурсообеспеченности и геостратегического положения, в контексте наличия пяти прибрежных государств, приобрел в юридическом и общественном восприятии формат «моря».

Единение и закрепление данного принципа получило воплощение в подписанной договаривающимися сторонами пяти прикаспийских государств Азербайджаном, Ираном, Казахстаном, Россией и Туркменистаном
Конвенции о правовом статусе Каспийского моря в августе 2018 г.

Достигнутые договоренности по разграничению Каспия являются результатом длительного переговорного процесса, осуществляемого в форматах разного уровня: совещания, встречи министров и глав государств, специализированные отраслевые конференции (межправительственная экономическая конференция прикаспийских государств в Астрахани в октябре 2008 г.). И, конечно, Каспийские саммиты глав государств, являются своеобразными ступенями эволюции переговорного процесса, свидетельствующими о валидности принципов консенсуса и простой формулы «взаимное уважение интересов, положенное на чуткость к партнеру по переговорам» $[8$, с. 5].

Предыстория возникновения необходимости решения проблемы определении статуса Каспия вытекает из геополитических перемен начала 1990-х гг., появление новых государств в регионе, в том числе наличие у них прибрежной зоны Каспия. Необходимость разграничения водоема кроется в его биологических, геологических богатствах, геополитическом положении, транзитной, экономической привлекательности.

Определение правового статуса Каспийского моря, по нашему видению является, с одной стороны, установлением восприятия водоема в качестве моря или озера, для чего применяются юридические, геологические, исторические, политические и другие критерии. В настоящее время здесь имеет место оригинальная трактовка определения правового статуса Каспийского водоема в качестве «моря-озера» в соответствии с принципами, закрепленными в Конвенции 2018 г.

С другой стороны, понимание правового статуса включает раскрытие сути межгосударственных отношений через взаимовосприятие субъектами их прав и обязанностей, что отражено в сформировавшейся системе многосторонних соглашений и договоренностей в различных областях взаимодействия по Каспию. Например, согласно Рамочной Конвенции по защите морской среды Каспийского моря (Тегеран, 4 ноября 2003 г.) и Протоколов к ней, «договаривающиеся стороны сотрудничают на двусторонней и многосторонней основе в разработке процедур, стандартов, обязанностей и прав для выполнения принятых условий» [3, с. 205]. Здесь определение правового статуса понимается в качестве установления и закрепления прав и правил поведения с целью упорядочения межгосударственных отношений и связей между договаривающимися сторонами, т.е. «само понятие правила поведения означает существование определенных связей между субъектами» [6, с. 2].

Кроме вышерассмотренных трактовок понимания 
и определения правового статуса Каспийского моря имеет место более наглядный, практический аспект, которым представляется проблема разграничения в контексте (определения) правового статуса Каспия. Какое из явлений приобретает здесь первичный характер, проблема определения правового статуса Каспия или вопрос его разграничения? Учитывая выше рассмотренные критерии данных явлений, полагаем, что определение правового статуса становится опорной, исходной точкой в процессе разрешения проблемы о государственной принадлежности Каспия, его ресурсов, недр, толщи поверхности вод, где необходимость дальнейшего процесса разграничения является вектором для упорядочивания проблематики правового статуса водоема.

Дальнейшее понимание и применение понятия о разграничении определяется критерием делимитации, которая подразумевает, с одной стороны, юридическое оформление договором линии государственной границы между сопредельными государствами, положение которой графически изображено на топографической карте с соответствующим ее описанием, которое может быть составной часть договора или приложением к нему [2, с.8]. С другой стороны, процесс делимитации границы определяет общие положения и направления государственной границы между сопредельными государствами путем переговоров, при этом материалы делимитации служат основанием для последующего этапа определения границы - проведения ее на местности (демаркации).

Таким образом, делимитация включает множество процессов, начиная от определения общих принципов и положений между договаривающимися сторонами путем переговоров и, заканчивая получением историкоюридического источника с достигнутыми согласованными инструкциями между сопредельными государствами о дальнейшем практическом исполнении договоренностей, где, естественно, необходимо наличие сформированного понимания определения правового режима и правового статуса разграничиваемого объекта.

Многоплановость процесса делимитации имеет множество неоднозначных вопросов, требующих совместного многостороннего взаимодействия для достижения грамотного компромиссного решения, среди которых, во-первых, вопрос национального суверенитета сопредельных прикаспийских государств. В контексте выражения государственного суверенитета стран региона содержатся понятия национальных зон и национальных секторов, которые, в результате достигнутых соглашений в августе 2018 г. и по настоящий момент рассматриваются в качестве участков дна и недр Каспийского моря и закрепленных за странами-подписантами комплекса документов на Пятом каспийском саммите. Здесь распространяются национальные компетенции стран, занятых освоением ресурсов дна и недр, осуществляющих правомерные мероприятия хозяйственно-экономической, научно-исследовательской и других видов деятельности в рамках собственной, согласованной с сопредельными государствами, юрисдикции. Во-вторых, вопрос о разграничении дна и недр, рассматриваемых в контексте делимитации Каспия, содержит специфический сценарий его разрешения.

Методика определения «прямых исходных линий, являющихся прямыми линиями, соединяющими соответствующие точки берегов и образующие исходную линию в местах, где береговая линия извилиста или где имеется вдоль берега и в непосредственной близости к нему цепь островов» [3, с. 518] определяется отдельными соглашениями между сопредельными прикаспийскими государствами. Такой формат межгосударственного взаимодействия адаптирован, с одной стороны, с учетом специфического определения правового статуса Каспия, его представления как «море-озеро»; с другой стороны, достигнутое компромиссное решение является показателем особых отношений, сформированных внутри «каспийской пятерки» в результате длительного многоуровневого и многостороннего переговорного процесса.

При этом наличие явного результата не отменяет дальнейшую работу по делимитации водоема (вопрос ратификации конвенции о правовом статусе Каспийского моря, заключение отдельных соглашений между всеми Сторонами, деятельность Рабочей группы над Соглашением о прямых исходных линиях по Каспию), что требует наличия постоянной переговорной платформы. Подобная концепция в вопросе делимитации Каспия, полагаем, соответствует современным международным политическим условиям, закладывает основу для оперативного принятия решений по текущим и возникающим вопросам в хозяйственно-экономической, общественно-политической областях, а также закрепляет прозрачность в вопросах компетенции и ответственности государств. Достигнутый компромисс является результатом длительных переговоров с грамотно выверенными критериями взаимодействия.

Полагаем, что сформированная система договоренностей между странами-подписантами Актаутской Конвенции 2018 г. имеет прочную основу для дальнейшего сотрудничества в различных областях. И здесь значение вопроса о правовом статусе Каспийского моря приобретает роль идентификатора общей межгосударственной политики в регионе. Достигнутые в настоящий момент договоренности подтверждают намерения и закрепляют вектор внешней политики прибрежных государств.

Так закрепленные в Договоре о Евразийском экономическом союзе от 2014 г. специальные принципы в 
области межгосударственной торговли, а именно национальный режим при торговле услугами, учреждениями и деятельности (п. 21 - 26) и режим наибольшего благоприятствования при торговле услугами, учреждениями и деятельности (п. 27 - 29), предопределяют ожидания и формируют обстоятельства, приемлемые для каждого государства-члена.

Таким образом, учреждение и закрепление на практике такого рода "добрососедских», заранее заданных экономических отношений демонстрирует возможность подобного сценария и в области делимитации Каспийского моря. Взаимность и компромисс воплощают условия для существования единого водоема на политической карте мира, где распределение не означает разделение. На пути к достижению актаутских соглашений между прикаспийскими государствами отдельные заинтересованные стороны использовали формат двух-, трехсторонних договоренностей по разграничению Каспийского моря в целях осуществления недропользования, что приводит к тенденции условного деления водоема на Северную и Южную сферу влияния [3, с. 334].

Как было сказано выше, Конвенция о правовом статусе Каспийского моря предусматривает, что территориальные вопросы (разграничение компетенции в области дна и недр Каспия) имеют потенциал решения на уровне двух- и трехсторонних переговоров. При этом, ориентируясь на первичные договоренности по северной части водоема, существует вероятность, что прикаспийские государства столкнутся с парадоксальной тенденцией двоичного раздела: на север и юг. Объективно полагать, что такой сценарий нежелателен для стран «каспийской пятерки», т.к. дихотомическое деление подразумевает обособление и противопоставление, что противоречит политике межгосударственного партнерства.

Соглашение между Российской Федерацией и Республикой Казахстан о разграничении дна северной части Каспийского моря в целях осуществления суверенных прав на недропользование от 6 июля 1998 г. также и является пробным международно-правовым актом, закрепляющим принцип «общей воды». Здесь предпочтительным режимом толкования каспийских вод называется сохранение в общем пользовании водной поверхности, включая обеспечение свободы судоходства, согласованных норм рыболовства и защиты окружающей среды, что разграничивается Сторонами по срединной линии, модифицированной на основе принципа справедливости и договоренности сторон.

Подчеркивая оригинальность исторического решения об определении правового статуса Каспия и распространении юрисдикции прикаспийских государств к водоему, отметим принципиальную разницу в контексте делимитации дна и недр водоема и его покрывающих вод. Достижение отдельных договоренностей предписывается прибрежным государствам по вопросам компетенции для дна и недр Каспийского моря. Здесь вопрос имеет подвижные, гибкие механизмы для дальнейшей работы. В то время как проблема определения границы в водах получает однозначный ответ в виде формулы - 15:10: общее, где 15 миль есть водное пространство, находящееся в прибрежной зоне соответствующего суверенного государства, 10 миль - рыболовные зоны и далее совокупные покрывающие воды, находящиеся в общей пятисторонней компетенции. Таким образом, общая водная поверхность используется странами-подписантами на основании комплекса достигнутых юридически оформленных договоренностей в различных сферах деятельности.

Исторически Каспийское море было объектом совместного использования прибрежными государствами; проблема национальных зон (определение границы в водах, делимитация дна и недр) стали новым явлением в вопросе национальной государственной принадлежности Каспия [1, с. 56]. Но заметим, что Конституция Каспия (как еще называют Конвенцию о правовом статусе Каспийского моря) частично сохранила традицию общего использования и совокупной компетенции/ответственности прибрежными государствами.

Здесь имеет место вопрос о взаимозависимости решений по вопросам разграничения покрывающих вод, дна и недр водоема. Но международно-правовые принципы и достигнутые договоренности сторон конкретно обозначают, что «методика делимитации водных пространств не повлияет на разграничение дна, ни в коей мере не предопределит исхода соответствующих переговоров» [4].

В целом достигнутые «каспийской пятеркой» договоренности выражают, во-первых, непосредственную возможность историко-юридического определения статуса Каспия. Во-вторых, система соглашений между прибрежными государствами, флагманом которой в настоящий момент является Конвенция 2018 года, демонстрирует присутствие этического аспекта в переговорном процессе и межгосударственном взаимодействии. Так Конвенция, совокупно с подписанными соглашениями и протоколами, закрепляет основные принципы, согласно которым следует действовать прибрежным государствам в отношении Каспия и государств-партнеров. Кроме того, фиксируются их права и обязанности в специализированных областях, соблюдение которых жизненно важно для всего водоема. Стратегия по использованию Каспия грамотно рассматривает водоем в качестве общего достояния, а не средоточия ресурсов.

Кроме того, Конвенцией открыта платформа для двух-, трехсторонних соглашений между прибрежными 
государствами, что предопределяет гибкость условий, создает возможность для учета обстоятельств и альтернатив. Вероятно, такой формат договоренностей будет способствовать прозрачности партнерских отношений между государствами. И первым своеобразным тестом на качество отношений и готовность к реализации договоренностей является ратификация соглашений и, прежде всего, Конвенции о правовом статусе Каспийского моря странами-подписантами. Данный акт выступает как необходимое юридическое мероприятие, а также демонстрирует признание и готовность следовать в контексте совместно принятых общих решений.

Азербайджан, Казахстан, Туркменистан в течение года с момента подписания Актаутской Конвенции осуществили соответствующие внутренние процедуры. Ратификационную эстафету приняла Российская Федерация, завершившая процедуру по ратификации осенью 2019 г., признание и соблюдение условий достигнутых соглашений обличены в форму федерального закона [7].

В настоящий момент проблема ратификации Конвенции стоит перед Ираном, что обусловлено внутриполитическими обстоятельствами. По результатам проведения первого тура парламентских выборов была отмечена рекордная низкая явка иранских граждан на избирательные участки. Кроме того, по данным, которые публикуют иранские СМИ, абсолютное большинство в парламенте себе уже обеспечили себе консерваторы, а не реформисты, что может затруднить работу правительства Хасана Роухани [5], и отдаляет процедуру подтверждения достигнутых совместных межгосударственных решений в отношении судьбы Каспия.

Таким образом, в контексте достигнутых договоренностей проблема делимитации Каспия приближается к стадии ее практического осуществления (с учетом возникающих обстоятельств, замедляющих процесс разграничения водоема по установленному принципу). Установленные государственные границы, естественно, являются пространственным (суша, воды, недра, воздушное пространство) пределами действия государственного суверенитета, независимо от внешней политики и направленности верховной государственной власти во внутренних делах. При этом вопрос разграничения Каспия, решение которого имеет незавершенный характер, находится в промежуточном, нестабильном состоянии, что делает Каспийское море и успешное межгосударственное сотрудничество зависимыми от множества как внешних, так и внутренних обстоятельств.

Кроме того, промежуточное положение вопроса о Каспии определяется отсутствием единой демаркационной методики. Взаимосвязанность процессов делимитации и демаркации обуславливает их подвижность и незавершенность. Во-первых, под демаркацией понимают деятельность по проведению государственной границы на определенной местности, которая осуществляется на основании достигнутых договоренностей по делимитации. Т.е. демаркация является следствием, практическим исполнением юридических предписаний по разграничению конкретной поверхности. Во-вторых, демаркация является не только техническим процессом по обозначению делимитационных установок (с использованием специальных демаркационных средств, механизмов и учреждений - демаркационные карты, пограничные знаки, комиссии по демаркации границы, сами демаркационные работы и пр.), но и фиксирует внешнеполитическую, межгосударственную деятельность государственных органов заинтересованных стран-участников, работу их национальных делегаций.

Таким образом, несмотря на следование демаркационного процесса после делимитационной работы, тезис проведения установленной государственной границы на определенной местности закладывается на стадии разграничения и является его конечной целью. Однозначное понимание прохождения государственной границы становится квинтесенцией во взаимодействии «каспийской пятерки» в русле системы делимитация - демаркация. «Демаркация государственной границы завершает распределение территорий между сопредельными государствами, поэтому после демаркации государственной границы не должно оставаться неопределенностей в прохождении государственной границы» [2, с. 134].

Итак, правовой статус Каспийского моря является широким понятием, включающим различные явления, каждое из которых заслуживает особого внимания и четкость понимания с учетом междисциплинарной специфики вопроса: определение и разграничение, разграничение и делимитация, делимитация и ратификация, делимитация и демаркация; и здесь мы приходим к следующим выводам. Во-первых, данные процессы имеют собственные частные критерии в контексте разграничения и делимитации водоема, привносящие структурированность и системность в понимание международно-правового статуса Каспия. Вопрос о разграничении дна и недр, определение границы в водах и толкование режима каспийских вод, режим наибольшего благоприятствования, национальные зоны (сектора), национальный суверенитет, северные и южные сферы, прямые исходные линии, покрывающие воды и т.д. есть то, что составляет историко-правовое понимание положения Каспийского моря в настоящем. Во-вторых, система государственно-волевых, международно-правовых юридических актов по Каспию, которую возглавляет Конвенция о правовом статусе Каспийского моря, продолжает расширяться и стабилизироваться, где качество делимитационных и демаркационных процессов становится катализатором межгосударственных отношений в Прикаспийском регионе. 


\section{ЛИТЕРАТУРА}

1. Вартаньян Э.Г. Каспийский регион: проблемы и решения // Грани. Краснодар, 2002. № 3. С. 54-58.

2. Делимитация и демаркация государственных границ: актуальные вопросы и способы их решения [Электронный ресурс]: аналитический сборник ОБСЕ 2017. 154 c. URL: https://www.osce.org/ru/secretariat/363471?download=true (дата обращения: 4.03.2020).

3. Каспий: международно-правовые документы / сост. С.С. Жильцов, И.С. Зонн, А.Г. Костяной, А.В. Семенов - М.: Международные отношения, 2018. 568 с.

4. Качалова А. Об особенностях переговорного процесса по Конвенции о правовом статусе Каспийского моря [Электронный ресурс]: Международная жизнь. 2019. №7. URL: https://interaffairs.ru/jauthor/material/2210 (дата обращения: 14.03.2020)

5. Парламентские выборы в Иране. [Электронный ресурс]: 23.02.2020. URL: https://ria.ru/20200223/1565127688.html (дата обращения: 26.02.2020).

6. Редких С.В. Понятие правового статуса: формально-правовой аспект // Проблемы в российском законодательстве. Юридический журнал. 2009. С. 1 - 3.

7. Федеральный закон «0 ратификации Конвенции о правовом статусе Каспийского моря» № 329-Ф3 от 01. 10. 2019 [Электронный ресурс]: справочноправовая система «Консультант-Плюс». URL: http://www.consultant.ru/document/cons_doc_LAW_334459/ (дата обращения: 15.03.2020).

8. Черненко Е. «Это не результат выкручивания рук». Посол по особым поручениям МИД РФ Игорь Братчиков — о Конвенции о правовом статусе Каспия [Электронный ресурс]: «Коммерсантъ». №167 от 14.09. 2018. URL: https://www.kommersant.ru/doc/3739592 (дата обращения: 19.02.2020).

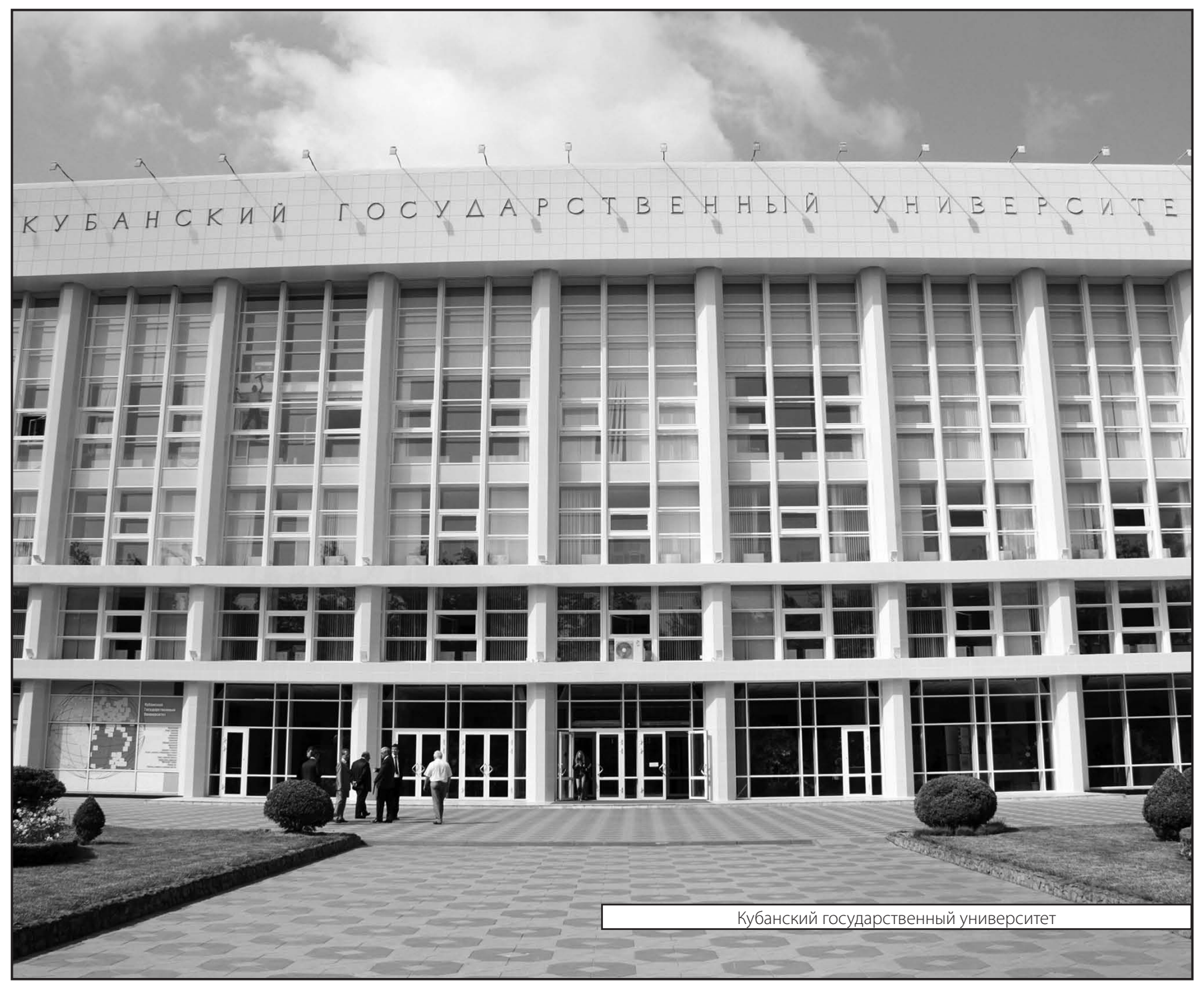

